\title{
Neoscytalidium dimidiatum Causing Canker, Shoot Blight and Fruit Rot of Almond in California
}

\author{
Mohamed T. Nouri, Department of Plant Pathology, University of California-Davis, Kearney Agricultural Research and Extension Center, \\ Parlier 93648; Daniel P. Lawrence, Department of Plant Pathology, University of California-Davis, Davis 95616; Mohammad A. \\ Yaghmour, University of California Cooperative Extension Kern County, Bakersfield 93307; and Themis J. Michailides ${ }^{\dagger}$ and Florent P. \\ Trouillas, ${ }^{\dagger}$ Department of Plant Pathology, University of California-Davis, Kearney Agricultural Research and Extension Center, Parlier
}

\begin{abstract}
Almond trees with trunk and branch cankers were observed in several orchards across almond-producing counties in California. Symptoms of cankers included bark lesions, discoloration of xylem tissues, longitudinal wood necrosis, and extensive gumming. Spur and shoot blight associated with rotted fruit were detected in two orchards in Kern County. The fungus Neoscytalidium dimidiatum was consistently recovered from the various cankers, infected fruit, and blighted shoots and its identity was confirmed based on phylogenetic and morphological studies. Phylogenetic analyses of the internal transcribed spacer, translation elongation factor $1-\alpha$, and $\beta$-tubulin genes comparing 47 strains from California with reference specimens within the family Botryosphaeriaceae and

coupled with detailed morphological observations validated the identity of the pathogenic fungus. Pathogenicity tests conducted in the field using 1- to 2-year-old branches inoculated with mycelium plugs or conidial suspensions and attached fruit inoculated with conidial suspensions fulfilled Koch's postulates. $N$. dimidiatum appeared highly virulent in almond-producing cankers of up to $22 \mathrm{~cm}$ in length within 4 weeks using mycelium plug inoculations as well as severe fruit rot combined with spur blight on the fruit-bearing spurs. This study reports, for the first time, the fungus $N$. dimidiatum as a pathogen of almond in California causing canker, shoot blight, and fruit rot. Disease symptoms are described and illustrated.
\end{abstract}

Almond (Prunus dulcis (Mill) D. A. Webb) is native to central and southwest Asia, and currently cultivated in California (United States), many Mediterranean countries, South Africa, and parts of South America and Australia (Gramaje et al. 2012). In California, almond is the most economically important crop commodity, accounting for $\$ 5.16$ billion in farm value in 2016 (California Department of Food and Agriculture: https://www.cdfa.ca.gov/statistics/). In total, $65 \%$ of California's almond crop is exported to countries such as Spain, China, India, and Germany. California is the largest almond producer worldwide providing over $80 \%$ of the world's supply (Almond Board of California 2016).

Almond trees are affected by various pests and pathogens. Among the wide range of diseases that affect almond production in California are canker diseases. Almond trunk and branch canker diseases are a major concern to the almond industry worldwide because they can affect young trees and become more prevalent as orchards age. Trunk disease pathogens generally attack woody parts of the host, causing symptoms such as cankers, dieback, and internal symptoms, including wedge-shaped necrosis as well as discoloration of the vascular tissues (Gramaje et al. 2012; White et al. 2011). In tree crops, dieback of scaffold branches may occur and eventually the whole tree may die. Canker diseases also affect tree longevity in orchards. Among some of the most common canker diseases that can affect almond are those caused by fungi in the Botryosphaeriaceae family (English et al. 1966, 1975; Inderbitzin et al. 2010; Ogawa and English 1991; Olmo et al. 2016). In California, canker diseases of almond caused by Botryosphaeriaceae spp. have been generally referred to as band canker or, in older reports, as Dothiorella canker, mainly affecting the

${ }^{\dagger}$ Corresponding authors: T. J. Michailides; E-mail: tjmichailides@ucanr.edu; and F. P. Trouillas; E-mail: flotrouillas@ucanr.edu

Funding: We thank the Almond Board of California for providing funding for this research.

*The $\boldsymbol{e}$-Xtra logo stands for "electronic extra" and indicates that three supplementary figures are published online.

Accepted for publication 4 March 2018.

(C) 2018 The American Phytopathological Society trunk of 3- to 6-year-old trees, as well as canopy cankers, mainly affecting branches and usually associated with pruning wounds (Inderbitzin et al. 2010).

Most species within the Botryosphaeriaceae family have a worldwide distribution and occur on a wide variety of plant hosts as saprobes, parasites, and endophytes (Slippers and Wingfield 2007). In California, species in the Botryosphaeriaceae family have been reported to cause diseases on many fruit and nut crops, including olive (Moral et al. 2010; Úrbez-Torres et al. 2013), almond (Doll et al. 2015; Inderbitzin et al. 2010), English walnut (Chen et al. 2014a), grapevine (Úrbez-Torres and Gubler 2009; Úrbez-Torres et al. 2006), avocado (McDonald and Eskalen 2011), citrus (Adesemoye et al. 2014), and pistachio (Chen et al. 2014b), as well as forest trees such as California bay laurel and coast live oaks (Lawrence et al. 2017a; Lynch et al. 2013), including riparian trees and bushes, which can serve as important sources of inoculum for nearby almond production areas (Inderbitzin et al. 2010). These fungi are associated with a variety of different symptoms such as leaf, shoot, and fruit blights; stem and branch cankers; dieback; and gummosis. Plantpathogenic fungi in the Botryosphaeriaceae family are commonly identified based on the morphology of the asexual morph, which is most frequently observed in nature. Although it is a quick and inexpensive method, it has led to a confusing taxonomic history, whereby scientific names were based on morphological characteristics. Thus, the asexual morphology usually adopted to identify species of Botryosphaeriaceae is unable to resolve closely related species (Slippers et al. 2004). To overcome this problem, DNA-based phylogenetics have allowed for a more reliable method of species identification (Crous et al. 2006; Pavlic et al. 2009; Slippers et al. 2013). As a result, many new species in the Botryosphaeriaceae family have been described in recent years based on molecular data in conjunction with morphological characterization (Crous et al. 2006; Lawrence et al. 2017a; Pavlic et al. 2008; Phillips et al. 2005, 2013; Slippers et al. 2007).

The taxonomy of Neoscytalidium dimidiatum (Penz.) Crous \& Slippers (syn. Fusicoccum dimidiatum (Penz.) D. F. Farr), Hendersonula toruloidea Nattrass, $N$. hyalinum (C. K. Campb. \& J. L. Mulder) A. J. L. Phillips, M. Groenew. \& Crous), Scytalidium dimidiatum (Penz.) B. Sutton \& Dyko, and Torula dimidiata Penz. has had a tumultuous past because it produces two different asexual states known as synanamorphs that have been described by multiple authors. The 
coelomycetous morph produces pycnidia with conidia that are two septate, with a darkened central cell that resemble fusicoccumlike conidia, while the hyphomycetous morph produces powdery arthric chains of conidia that may form a central septum that resemble scytalidium-like conidia (Farr et al. 2005; Nattrass 1933; Sutton and Dyko 1989). Originally, $N$. dimidiatum was described as $T$. dimidiata Penz. by Penzig in 1882 based on the arthric synanamorph. About a half a century later, Nattrass (1933) described the pycnidial synanamorph as $H$. toruloidea in addition to noting the torula-like synanamorph. Sutton and Dyko (1989) revised the taxonomy of $H$. toruloidea, whereby they established the genus Nattrassia B. Sutton \& Dyko typified by Nattrassia mangiferae (Syd. \& P. Syd.) B. Sutton $\&$ Dyko (by synonymizing $H$. toruloidea) to accommodate the pycnidial morph. In addition, they synonymized $T$. dimidiata and
S. lignicola by circumscribing the new species S. dimidiatum (Penz.) B. Sutton \& Dyko to accommodate the arthric morph. Farr et al. (2005) were the first to show that authentic cultures studied by Sutton and Dyko that produce both the pycnidial and arthric synanamorphs cluster near Botryosphaeria Ces. \& De Not. within the family Botryosphaeriaceae. Therefore, based mainly on morphological similarity of the pycnidial morph with Fusicoccum Corda species, Farr et al. (2005) transferred N.. mangiferae (Syd. \& P. Syd.) B. Sutton $\&$ Dyko and $S$. dimidiatum to $F$. dimidiatum, creating polyphyly. Crous et al. (2006) revised the taxonomy of the Botryosphaeriaceae family based on a DNA phylogeny, whereby they revealed that the genus Scytalidium was polyphyletic, because the ex-type strain (S. lignicola CBS 233.57) clusters distantly to the Botryosphaeriaceae family; therefore, Scytalidium is taxonomically occupied.

Table 1. Isolates of Neoscytalidium dimidiatum sequenced and used for phylogenetic study and pathogenicity tests in this study

\begin{tabular}{|c|c|c|c|c|c|c|}
\hline \multirow[b]{2}{*}{ Species } & \multirow[b]{2}{*}{ Isolate } & \multirow[b]{2}{*}{ Host } & \multirow[b]{2}{*}{ Location $^{b}$} & \multicolumn{3}{|c|}{ GenBank accession number ${ }^{a}$} \\
\hline & & & & ITS & TEF-1 $\alpha$ & BT2 \\
\hline N. dimidiatum & KARE1791 & Prunus dulcis & Madera & MG021578 & MG021531 & MG021476 \\
\hline N. dimidiatum & KARE1792 & P. dulcis & Madera & MG021579 & MG021532 & MG021477 \\
\hline N. dimidiatum & KARE1793 & P. dulcis & Madera & MG021580 & MG021533 & MG021478 \\
\hline N. dimidiatum & KARE1794 & P. dulcis & Madera & MG021581 & MG021534 & MG021479 \\
\hline N. dimidiatum & 2-D76 & P. dulcis & Colusa & MG021582 & MG021535 & MG021480 \\
\hline N. dimidiatum & 2-D77 & P. dulcis & Fresno & MG021583 & MG021536 & MG021481 \\
\hline N. dimidiatum & 2-D79 & P. dulcis & Colusa & MG021584 & MG021537 & MG021482 \\
\hline N. dimidiatum & $5-\mathrm{B} 45^{\mathrm{b}}$ & P. dulcis & Fresno & MG021585 & MG021538 & MG021483 \\
\hline N. dimidiatum & 7-H09 & P. dulcis & Stanislaus & MG021586 & MG021539 & MG021484 \\
\hline N. dimidiatum & 9-F36 & P. dulcis & Fresno & MG021587 & MG021540 & MG021485 \\
\hline N. dimidiatum & $10-\mathrm{B} 05$ & P. dulcis & Kern & MG021588 & MG021541 & MG021486 \\
\hline N. dimidiatum & $10-\mathrm{B} 08$ & P. dulcis & Kern & MG021589 & MG021542 & MG021487 \\
\hline N. dimidiatum & $10-\mathrm{B} 10$ & P. dulcis & Kern & MG021590 & MG021543 & MG021488 \\
\hline N. dimidiatum & $10-\mathrm{H} 59$ & P. dulcis & Kern & MG021591 & MG021544 & MG021489 \\
\hline N. dimidiatum & 10-J79 & P. dulcis & Kern & MG021592 & MG021545 & MG021490 \\
\hline N. dimidiatum & $10-\mathrm{J} 81^{\mathrm{b}}$ & P. dulcis & Kern & MG021593 & MG021546 & MG021491 \\
\hline N. dimidiatum & $10-\mathrm{J} 83$ & P. dulcis & Kern & MG021594 & MG021547 & MG021492 \\
\hline N. dimidiatum & $10-\mathrm{J} 86$ & P. dulcis & Kern & MG021595 & MG021548 & MG021493 \\
\hline N. dimidiatum & KARE48 & P. dulcis & Fresno & MG021596 & MG021549 & MG021494 \\
\hline N. dimidiatum & KARE49 & P. dulcis & Fresno & MG021597 & MG021550 & MG021495 \\
\hline N. dimidiatum & KARE334 & P. dulcis & Madera & MG021598 & MG021551 & MG021496 \\
\hline N. dimidiatum & KARE335 & P. dulcis & Madera & MG021599 & MG021552 & MG021497 \\
\hline N. dimidiatum & KARE471 & P. dulcis & Kern & MG021600 & MG021553 & MG021498 \\
\hline N. dimidiatum & KARE472c & P. dulcis & Kern & MG021601 & MG021554 & MG021499 \\
\hline N. dimidiatum & KARE506 & P. dulcis & Merced & MG021602 & MG021555 & MG021500 \\
\hline N. dimidiatum & KARE507 & P. dulcis & Merced & MG021603 & MG021556 & MG021501 \\
\hline N. dimidiatum & KARE508 & P. dulcis & Merced & MG021604 & MG021557 & MG021502 \\
\hline N. dimidiatum & KARE509 & P. dulcis & Merced & MG021605 & MG021558 & MG021503 \\
\hline N. dimidiatum & KARE510 & P. dulcis & Madera & MG021606 & MG021559 & MG021504 \\
\hline N. dimidiatum & KARE511 & P. dulcis & Madera & MG021607 & MG021560 & MG021505 \\
\hline N. dimidiatum & KARE512 & P. dulcis & Madera & MG021608 & MG021561 & MG021506 \\
\hline N. dimidiatum & KARE513 & P. dulcis & Madera & MG021609 & MG021562 & MG021507 \\
\hline N. dimidiatum & KARE514 & P. dulcis & Madera & MG021610 & MG021563 & MG021508 \\
\hline N. dimidiatum & KARE1786 & P. dulcis & Fresno & MG021611 & MG021564 & MG021509 \\
\hline N. dimidiatum & KARE1787 & P. dulcis & Fresno & MG021612 & MG021565 & MG021510 \\
\hline N. dimidiatum & KARE1789 & P. dulcis & Fresno & MG021613 & MG021566 & MF991144 \\
\hline$N$. dimidiatum & KARE $1790^{\circ}$ & P. dulcis & Madera & MG021614 & MG021567 & MF991145 \\
\hline N. dimidiatum & 2-D53 & Ficus carica & Madera & MG021568 & MG021521 & MG021511 \\
\hline N. dimidiatum & 2-D54 & F. carica & Madera & MG021569 & MG021522 & MG021512 \\
\hline N. dimidiatum & 2-D56 & F. carica & Fresno & MG021570 & MG021523 & MG021513 \\
\hline N. dimidiatum & 2-D60 & F. carica & Madera & MG021571 & MG021524 & MG021514 \\
\hline N. dimidiatum & 2-D61 & F. carica & Madera & MG021572 & MG021525 & MG021515 \\
\hline N. dimidiatum & $3-\mathrm{F} 67$ & F. carica & Fresno & MG021573 & MG021526 & MG021516 \\
\hline N. dimidiatum & $3-F 68$ & F. carica & Fresno & MG021574 & MG021527 & MG021517 \\
\hline N. dimidiatum & $3-F 69$ & F. carica & Madera & MG021575 & MG021528 & MG021518 \\
\hline N. dimidiatum & $3-F 70$ & F. carica & Madera & MG021576 & MG021529 & MG021519 \\
\hline N. dimidiatum & $3-F 71$ & F. carica & Madera & MG021577 & MG021530 & MG021520 \\
\hline
\end{tabular}

${ }^{\mathrm{a}}$ ITS $=$ internal transcribed spacer, TEF- $1 \alpha=$ translation elongation factor $1 \alpha$, and BT2 $=\beta$-tubulin.

b Counties in California.

${ }^{\mathrm{c}}$ Isolates used for pathogenicity tests and in the temperature growth assay. 
Furthermore, Crous et al. (2006) established the new genus Neoscytalidium Crous \& Slippers in order to accommodate $F$. dimidiatum as Neoscytalidium dimidiatum, based on the powdery disarticulating production of aerial conidia and strongly supported DNA-based phylogenetic position within the Botryosphaeriaceae family, thus stabilizing a long and convoluted taxonomic history.

Recently, cankers showing intensely dark wood discoloration extending longitudinally, bark lesions, and gumming in trunks and branches were observed in almond orchards in several counties. In other instances, fruit rot associated with blighted spurs and shoots were detected commonly in two orchards in Kern County. A dark streaking generally developed in the xylem tissue of branches subtending blighted lateral shoots. Isolations from the various symptomatic tissues consistently generated a scytalidium-like fungus, which was suspected to belong to the family Botryosphaeriaceae. Considering the cosmopolitan distribution of the Botryosphaeriaceae spp. on virtually all woody hosts studied, it seems likely that additional species may be associated with almond trees in California. Therefore, the objectives of this study were to isolate, identify, and characterize the fungus causing cankers, shoot blight, and fruit rot on almond in California using a combination of molecular, morphological, and biological approaches.

\section{Materials and Methods}

Sampling and isolation of fungal strains. Field observations were made between 2014 and 2016 in the San Joaquin Valley of California, the most economically important and largest almond-growing region in the world. Symptoms of an unusual canker disease, including trunk and branch cankers, were observed in 14 almond orchards between 3 and 15 years old. Spur and shoot blight and rotted fruit were observed in two mature almond orchards. In total, 45 diseased samples were collected and taken to the laboratory for disease diagnosis. Isolations were made from pieces ( 3 by 3 by $3 \mathrm{~mm}$ ) of symptomatic tissues taken from the margin of necrotic and apparently healthy tissues after surface sterilizing in $0.5 \%$ sodium hypochlorite for $2 \mathrm{~min}$ and rinsing twice in sterile water and plating onto acidified potato dextrose agar (APDA; $2.6 \mathrm{ml}$ of $25 \%$ [vol/ $/ \mathrm{vol}]$ lactic acid per liter of medium). Isolation plates were incubated in the laboratory at room temperature (around $25^{\circ} \mathrm{C}$ ) with approximately $12 \mathrm{~h}$ of daylight and $12 \mathrm{~h}$ of darkness for 2 to 5 days. Emerging fungal colonies were transferred to potato dextrose agar (PDA). Single conidial cultures were established for each strain for further taxonomic and biological studies. Isolates collected for this study are described in Table 1 and all are maintained in the culture collection of the Department of Plant Pathology at the Kearney Agricultural Research and Extension Center, Parlier, University of California.

DNA extraction, polymerase chain reaction amplification, sequencing, and phylogenetic analyses. Total genomic DNA was extracted from 7-day-old colonies on PDA by gently scraping the mycelium with a sterile scalpel and following the manufacturer's protocol for the FastDNA Spin Kit (MP Biomedicals). Primer pairs ITS1/ITS4 (White et al. 1990), Bt2a/Bt2b (Glass and Donaldson 1995), and EF1-728F/EF1-986R (Carbone and Kohn 1999) were used to amplify the nuclear ribosomal DNA internal transcribed spacer (ITS) region, including ITS1, the intervening 5.8S ribosomal RNA gene, and ITS2; and portions of the $\beta$-tubulin (BT2) and translation elongation factor $1-\alpha$ (TEF-1 $\alpha)$, respectively. Amplification products were visually inspected on a $1.5 \%$ agarose gel for presence and size via electrophoresis ( $120 \mathrm{~V}$ for $25 \mathrm{~min}$ ) followed by purification using ExoSap-IT Product Cleanup Reagent (Thermo Fisher Scientific; Affymetrix). Polymerase chain reaction (PCR) amplicons were sequenced in both directions using an ABI Prism 3730 DNA Sequencer (Perkin-Elmer) at the Division of Biological Sciences Sequencing Facility at the University of California, Davis. DNA chromatograms were edited and aligned with ContigExpress Vector NTI Advance 10 (Invitrogen); then, consensus sequences were subjected to BLASTn queries at the National Center for Biotechnology Information to obtain preliminary identifications and sequences with high similarity to ex-type or representative specimens for phylogenetic reference (Table 2). Additionally, ITS and TEF- $1 \alpha$ sequences were subjected to BLASTn searches of the new, curated TrunkDiseaseID.org database (Lawrence et al. 2017 b) to ensure an accurate identification because GenBank is not curated for accurate species diagnosis. Sequences obtained in this study have been deposited in GenBank (Table 1). Multiple sequence alignments were conducted in MEGA v. 6 (Tamura et al. 2013) and manually adjusted where necessary in Mesquite v. 3.10 (Maddison and Maddison 2016). Alignments were submitted to TreeBASE under the accession number S21604. Phylogenetic analyses were performed in MEGA v. 6 utilizing two different optimality search criteria, maximum likelihood (ML), and maximum parsimony (MP).

Table 2. Isolates and sequences from other studies used in phylogenetic analyses for this study

\begin{tabular}{|c|c|c|c|c|c|c|}
\hline \multirow[b]{2}{*}{ Species } & \multirow[b]{2}{*}{ Isolate $^{\mathbf{b}}$} & \multirow[b]{2}{*}{ Host } & \multirow[b]{2}{*}{ Location } & \multicolumn{3}{|c|}{ GenBank accession number ${ }^{\mathrm{a}}$} \\
\hline & & & & ITS & TEF-1 $\alpha$ & BT2 \\
\hline Botryosphaeria fusispora & MFLUCC 10-0098 & Caryota sp. & Thailand & JX646789 & JX646854 & JX646839 \\
\hline B. cortices & CBS 119047 & Vaccinium corymbosum & New Jersey & DQ299245 & EU017539 & EU673107 \\
\hline B. dothidea & CBS 115476 & Prunus sp. & Switzerland & AY236949 & AY236898 & AY236927 \\
\hline B. agaves & MFLUCC 11-0125 & Agaves sp. & Thailand & JX646791 & JX646856 & JX646841 \\
\hline Macrophomina phaseolina & CBS 227.33 & Zea mays & Unknown & KF531825 & KF531804 & KF531806 \\
\hline Cophinforma eucalypti & MFLUCC 11-0425 & Eucalyptus sp. & Thailand & JX646800 & JX646865 & JX646848 \\
\hline C. mamane & CBS 117444 & Eucalyptus sp. & Venezuela & KF531822 & KF531801 & KF531802 \\
\hline Neoscytalidium dimidiatum & CBS 251.49 & Juglans regia & California & KF531819 & KF531797 & KF531799 \\
\hline N. dimidiatum & CBS 499.66 & Mangifera indica & Mali & KF531820 & KF531798 & KF531800 \\
\hline N. dimidiatum & CBS 145.78 & Homo sapiens & United Kingdom & KF531816 & KF531795 & KF531796 \\
\hline Neofusicoccum mangiferae & CBS 118532 & M. indica & Australia & AY615186 & DQ093220 & AY615173 \\
\hline N. mediterraneum & CBS 121718 & Eucalyptus sp. & Greece & GU251176 & GU251308 & GU251836 \\
\hline N. parvum & CBS 110301 & Vitis vinifera & Portugal & AY259098 & AY573221 & EU673095 \\
\hline Guignardia bidwellii & CBS 111645 & Parthenocissus quinquefolia & Missouri & FJ824766 & FJ824772 & FJ824777 \\
\hline G. citricarpa & CBS 102374 & Citrus aurantium & Brazil & FJ824767 & FJ538371 & FJ824778 \\
\hline G. philoprina & CBS 447.68 & Taxus baccata & United States & FJ824768 & FJ824773 & FJ824779 \\
\hline Neoscytalidium novaehollandiae & WAC 13275 & M. indica & Australia & GU172400 & GU172432 & N/A \\
\hline N. novaehollandiae & WAC 13303 & M. indica & Australia & GU172398 & GU172430 & N/A \\
\hline Lasiodiplodia citricola & 7-E80 & J. regia & Tulare Co., CA & KC357300 & KC357312 & KC357306 \\
\hline N. dimidiatum & 150655 & Hylocereus undatus & Florida & KT803701 & N/A & N/A \\
\hline N. dimidiatum & UTHSCSA DI 14-340 & Homo sapiens & Texas & KM357894 & N/A & N/A \\
\hline
\end{tabular}

a ITS $=$ internal transcribed spacer, TEF- $1 \alpha=$ translation elongation factor $1 \alpha$, and BT2 $=\beta$-tubulin. N/A = not available.

b Isolate numbers in bold represent ex-type specimens. 
For ML analyses, MEGA was used to infer the best model of nucleotide substitution for each dataset using the Bayesian information criterion (BIC). Each ML analysis used the nearest-neighbor interchange heuristic search method and clade support was estimated by 1,000 bootstrap replicates. MP analyses consisted of heuristic searches with
1,000 random sequence additions implemented with the tree-bisectionreconnection algorithm, with gaps treated as missing data. Bootstrap analyses were performed as above. Sequences of genus Phyllosticta Pers. (Botryosphaeriales, Phyllostictaceae) served as the outgroup taxon in all analyses.
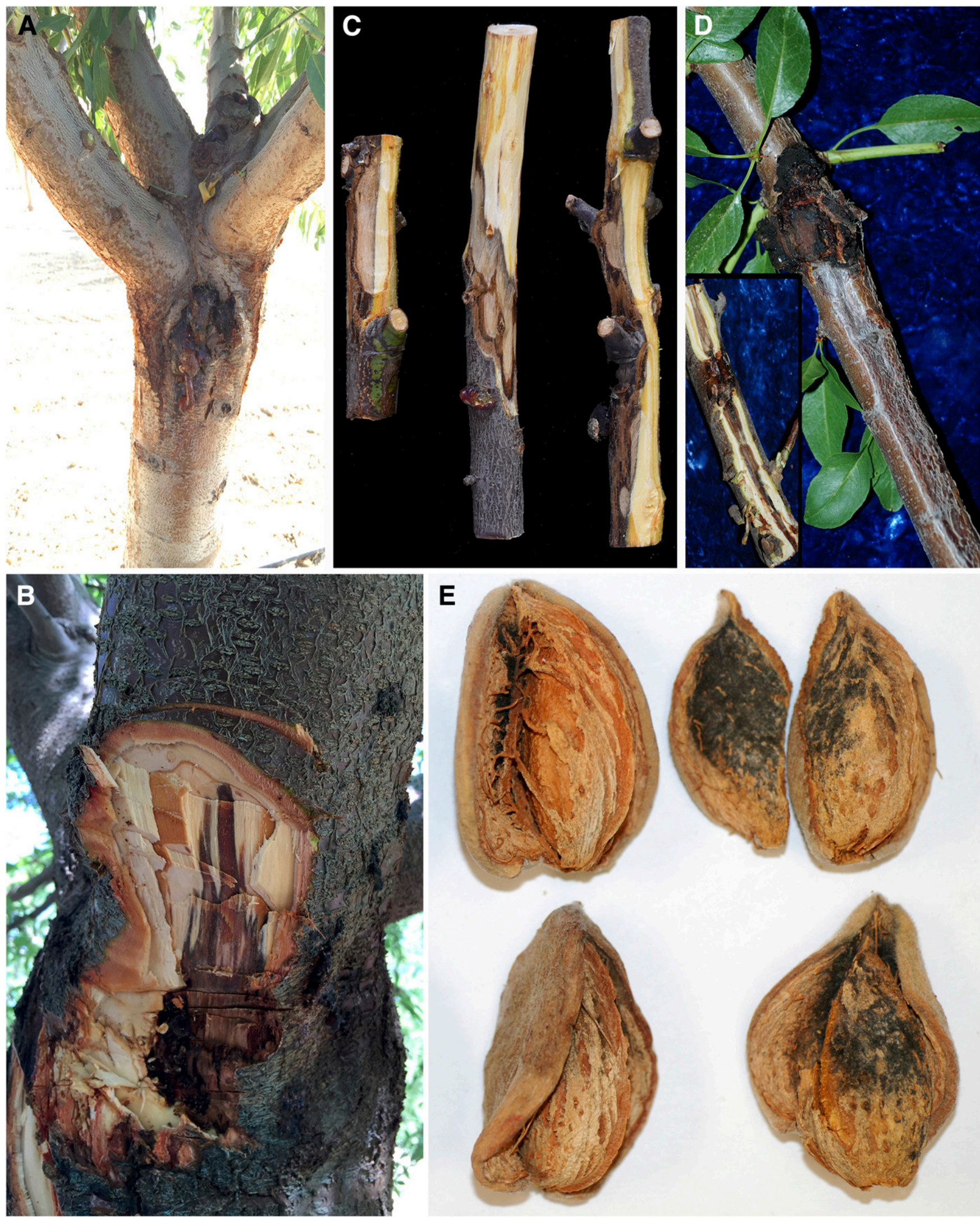

Fig. 1. Symptoms and signs of Neoscytalidium disease in almond observed in the field. A and B, Gumming and internal symptoms in the trunk. $\mathbf{C}$ and $\mathbf{D}$, Typical longitudinal branch canker symptoms associated with Neoscytalidium dimidiatum. $\mathrm{E}$, Rotted fruit symptoms with sporulation of $N$. dimidiatum on the inner surface of hulls. 
Morphological characterization. Three isolates (KARE472, KARE510, and KARE1790) representing different counties were selected to study the anamorph morphology. Selected fungal isolates were grown on PDA plates incubated as described above at $25^{\circ} \mathrm{C}$ with white fluorescent lighting $40 \mathrm{~cm}$ above the Petri plates $(12 \mathrm{~h}$ of light and $12 \mathrm{~h}$ of darkness). Colony morphology was recorded twice, after $24 \mathrm{~h}$ and 12 days of incubation. Fungal colonies were also

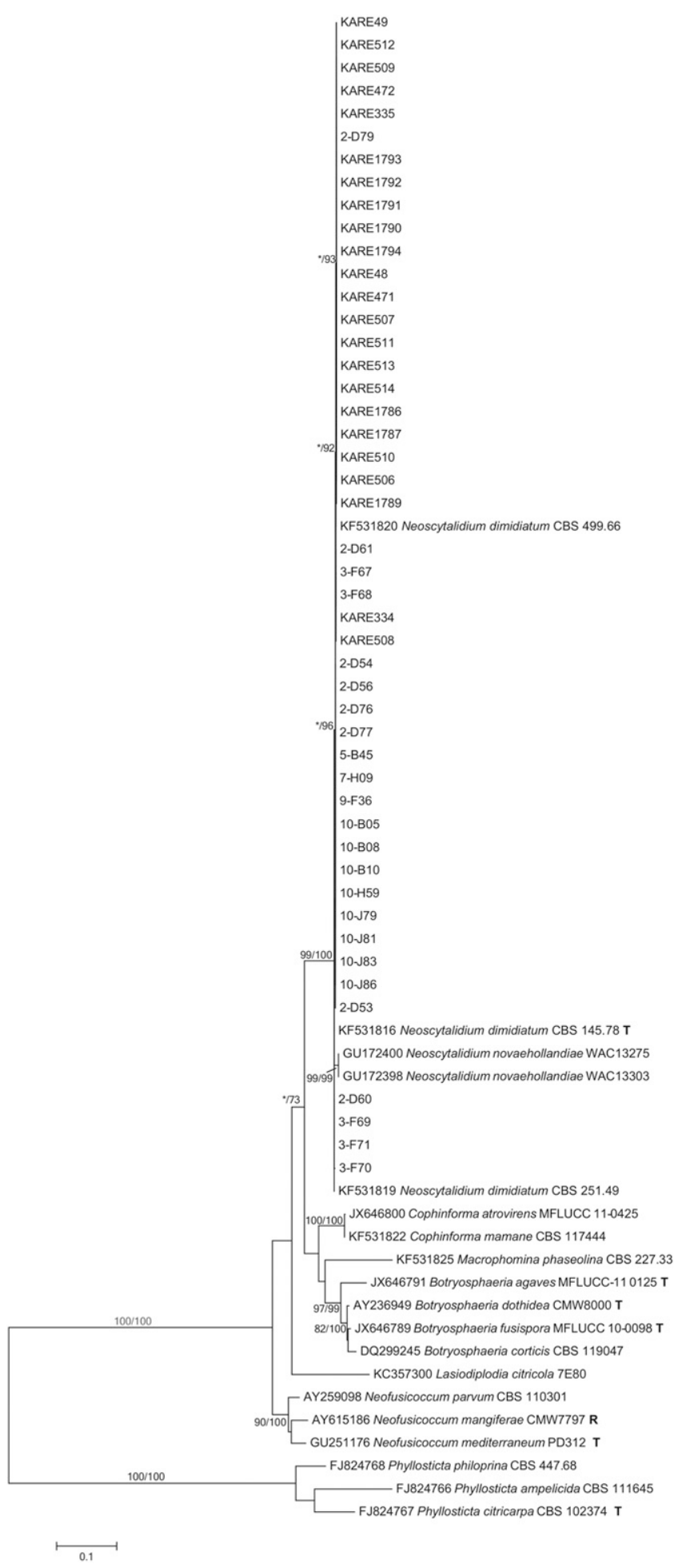

Fig. 2. Single most-likely tree (In likelihood -6009.5693) resulting from the analysis of the three-gene combined dataset (internal transcribed spacer, $\beta$-tubulin, and translation elongation factor $1 \alpha$ ). Numbers in front and after the slash represent maximum-likelihood and maximum-parsimony bootstrap values, respectively. Values represented by an asterisk were less than $70 \%$. Scale bar represents the number of substitutions per site. inspected weekly for up to 6 weeks for formation of pycnidia. For microscopic characterization, pycnidia containing conidia and arthroconidia produced by the hyphomycetous morph as well as mycelium fragments were mounted in sterile water on glass slides. Conidial dimensions of the two conidial types included length and width of 40 conidia for each of the three selected strains were measured at $\times 400$ magnification using a Leica compound microscope (Leica DM2000 LED Microscope).

The optimal temperature for growth was determined using the same three representative strains reported above (KARE472, KARE510, and KARE1790). A 5-mm mycelial plug taken from the margin of an actively growing colony was placed in the center of an $85-\mathrm{mm}$ diameter PDA Petri plate. Cultures of four replicates for each isolate were incubated at temperatures of 10 to $40^{\circ} \mathrm{C}$ in $5^{\circ} \mathrm{C}$ increments. Plates were incubated in the dark, and two measurements of colony diameter at right angles to each other were taken daily until the fastest growing culture reached the plate edge. Average colony diameters per $48 \mathrm{~h}$ of growth were obtained for each of the seven temperatures tested $\left(10,15,20,25,30,35\right.$, and $\left.40^{\circ} \mathrm{C}\right)$. The experiment was repeated once.

Pathogenicity tests. Branch inoculations. Two sets of branch inoculation assays were conducted using two representative strains from different geographical origins (5-B45 and 10-J81) with either colonized PDA plugs (assay 1) or conidial suspensions (assay 2) in the field at the Kearney Agricultural Research and Extension Center (KARE) in Parlier, CA. Both assays consisted of two independent experiments of inoculation of 101 - to 2-year-old branches on each of 10 10-year-old almond trees. Assay 1 was conducted in February 2015 following the method described by Chen et al. (2014b). The susceptibility of two almond cultivars (Nonpareil and Butte) was evaluated because they predominate in the Central Valley of California. The outer bark at the inoculation site was sanitized with $70 \%$ ethanol and a 5-mm wound was made using a sterile cork borer. A 5-mm mycelial plug was excised from the margin of a 7-day-old culture and inserted in the wound, which was then sealed and wrapped with parafilm. Ten branches were mock inoculated with noncolonized PDA plugs as above to serve as negative controls. Inoculated and mock-inoculated branches were collected after 1 month and the length of wood discoloration (LWD) was measured above and below the point of inoculation for each branch. The data satisfied the normality and homogeneity of variance requirements of analysis of variance (ANOVA) according to Shapiro-Wilk's and Bartlett's tests, respectively. ANOVA were performed in Statistix 10 (Analytical Software) in order to evaluate differences in the extent of the LWD between the control and fungal treatments. Pairwise mean differences compared with the mock-inoculated controls were analyzed with Dunnett's test $(P>0.05)$.

A second assay (assay 2) was conducted in July 2015 using the almond cultivar Carmel for the purpose of examining symptoms production in branches using conidial suspension as the inoculation method. Inoculations were made by removing the bark of branches with a 5-mm cork borer and pipetting a $50-\mu l$ drop of a suspension of $1 \times 10^{6}$ conidia (arthrospores) per milliliter directly into the wound, followed by application of petroleum jelly to retain wetness. Sterile water mock inoculations served as negative controls. Inoculated and mock-inoculated branches were collected after 1 month and the presence cankers as well as gumming was recorded. Ten wood pieces ( 2 by 2 by $5 \mathrm{~mm}$ ) taken from the margin of developing cankers were surface sterilized in $0.5 \%$ sodium hypochlorite solution for 2 min, rinsed twice with sterile water, and plated on APDA plates. Isolation plates were incubated in darkness at $25^{\circ} \mathrm{C}$ for 7 days in an attempt to recover the inoculated fungus and to fulfill Koch's postulates.

Fruit inoculations. The same fungal isolates and almond cultivars used for the inoculation of the branches in assay 1 were also used for field inoculation of attached almond fruit. Two experiments in the beginning and middle of June 2015 were conducted in a 12-year-old orchard by injecting through the hull split between the inner surface of hulls and shell using a sterilized hypodermic needle to inoculate either a $40-\mu l$ drop of a spore suspension of $1 \times 10^{5}$ spores $/ \mathrm{ml}$ or sterile 

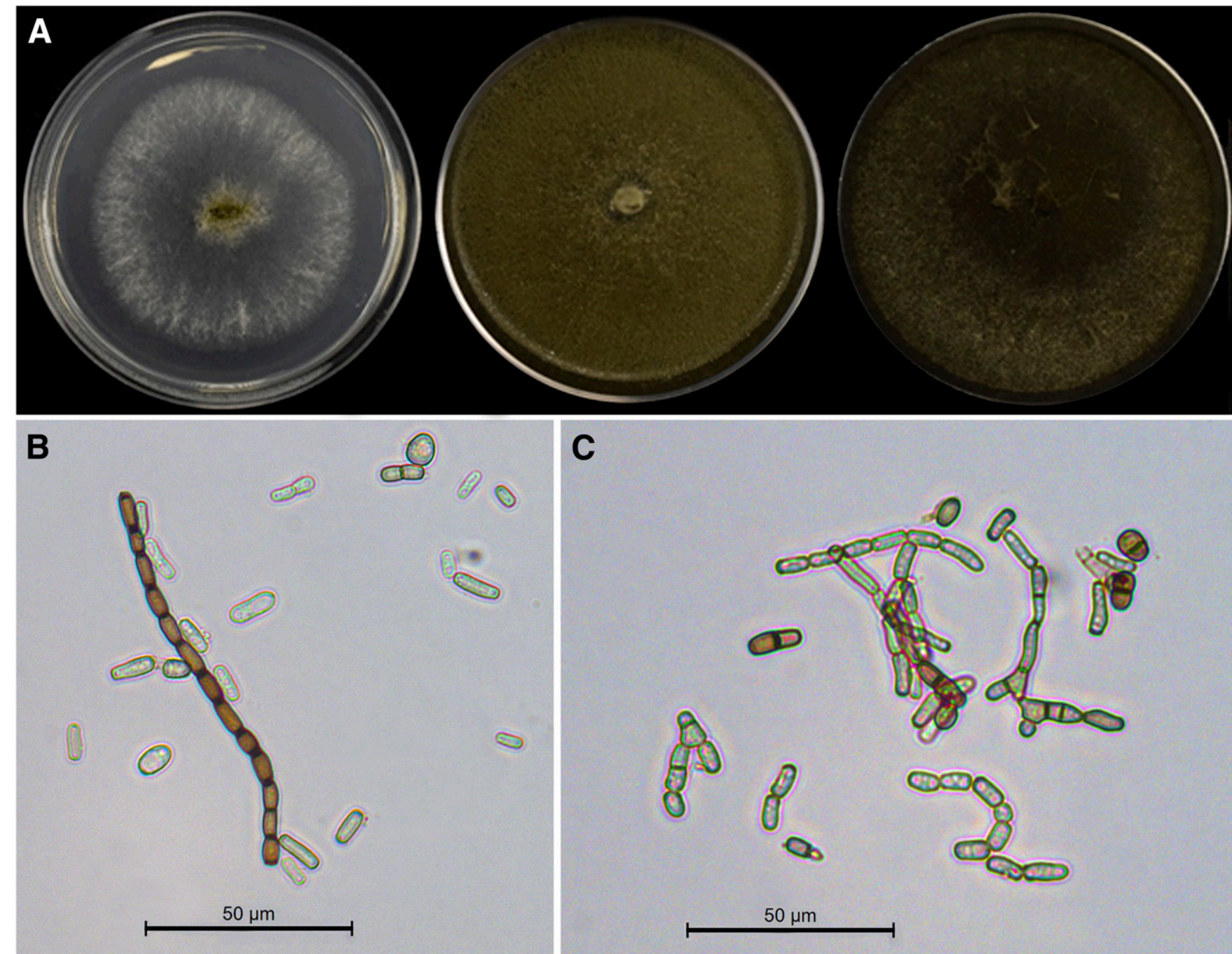

C
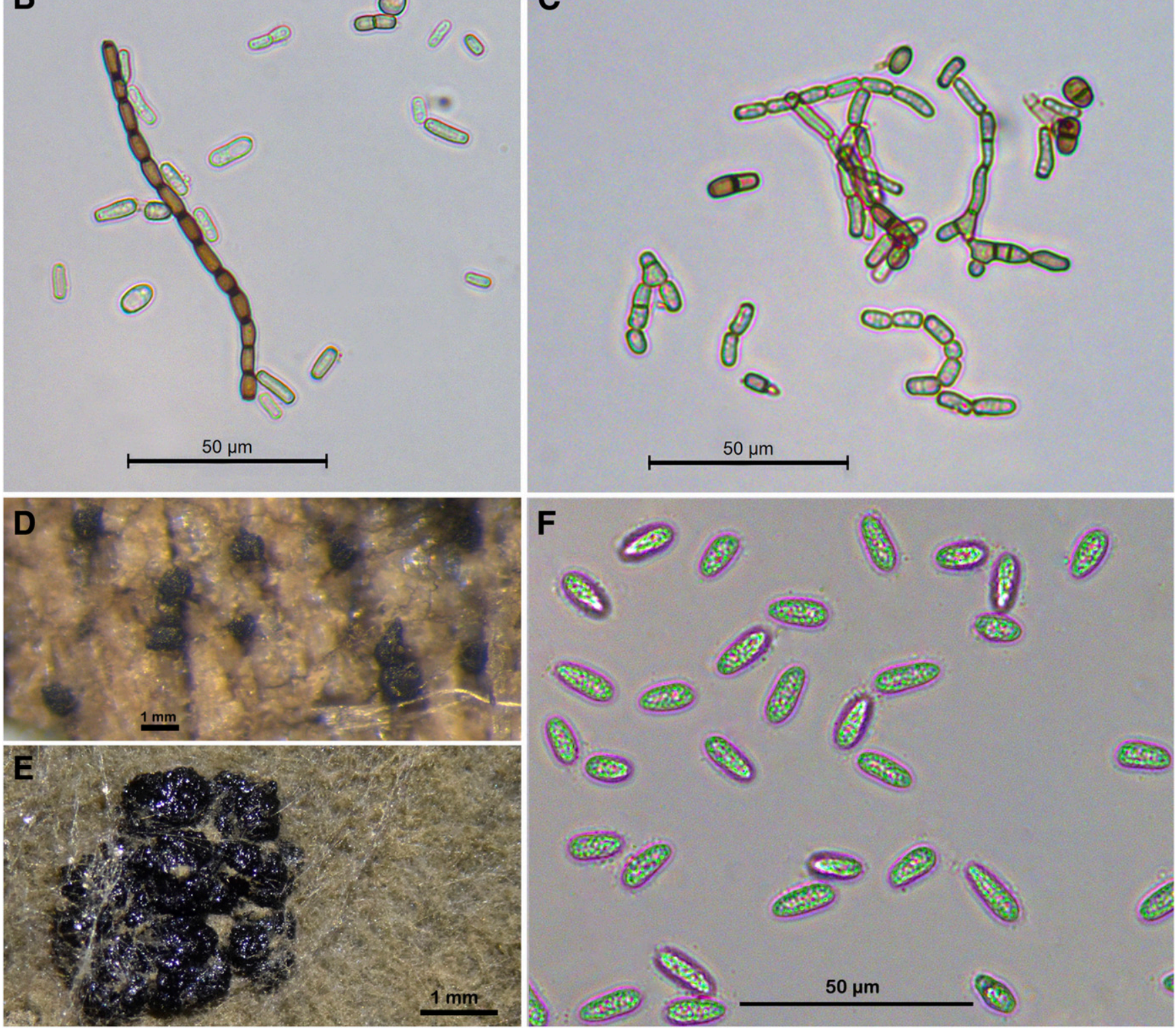

Fig. 3. Morphological characteristics of Neoscytalidium dimidiatum. A, Colonies on potato dextrose agar (PDA) (left: $24 \mathrm{~h}$ of incubation at $25 \pm 1^{\circ} \mathrm{C}$ and middle and right: 12 days of incubation at $25 \pm 1{ }^{\circ} \mathrm{C}$ ); $\mathbf{B}$ and $\mathbf{C}$, scytalidium-like anamorph showing various shapes and maturity stages of arthroconidia segmenting from hyphae; $\mathbf{D}$, pycnidia formed on a woodchip 4 weeks after isolation and incubation in PDA at $25 \pm 1{ }^{\circ} \mathrm{C}$; $\mathbf{E}$, pycnidia formed on a 4-week-old colony on PDA (pure culture) at $25 \pm 1{ }^{\circ} \mathrm{C}$; and $\mathbf{F}$, fusicoccum-like pycnidial conidia (immature). 
water for inoculated and mock-inoculated fruit, respectively. Results of the experiments were recorded 7 to 10 days after inoculation.

\section{Results}

Disease symptoms and distribution. Trunk cankers and branch cankers associated with dieback were observed in 14 orchards distributed in Colusa, Merced, Madera, Fresno, Stanislaus, and Kern Counties in California. Cankers in trunks were detected in young trees (third to fifth leaf) near pruning wounds (Fig. 1A and B). Branch cankers were found in mature trees ( 8 to 15 years old) and were associated with pruning wounds and other wounds (Fig. 1C). Cankers developed longitudinally, causing dark discoloration of xylem tissues, and were often associated with extensive gumming. Symptoms, including dead peduncles and rotted fruit, which led to spur and shoot blight were observed in two mature orchards in Kern County. Shoot blight associated with infected fruit developed a dark discoloration (streaking) of the xylem tissues in the previous year's branches which produced excess sap (Fig. 1D), eventually producing a canker. Sap was initially amber in color but later became dark. Furthermore, fruit infected by the pathogen developed abundant sporulation on the inner surface of the hulls (hull rot) (Fig. 1E). The putative pathogen was isolated from symptomatic fruit and branches in different almond cultivars, including Nonpareil, Independence, Fritz, Monterey, Carmel, and Padre.

Phylogenetic analyses. For ML analyses, the best-fit model of nucleotide substitution was deduced based on the BIC (K2+G for ITS, $\mathrm{T} 92+\mathrm{G}$ for BT2, T92+G+I for TEF-1 $\alpha$, and Tamura-Nei+G for the combined analysis). Alignment of 66 ITS sequences resulted in a 519-character dataset (326 characters were constant, 148 characters were parsimony informative, and 45 characters were parsimony uninformative). MP analysis produced six equally most-parsimonious trees of 313 steps and a consistency index (CI) and retention index (RI) of
0.7765 and 0.8856 , respectively. ML and MP analyses revealed that 47 Neoscytalidium isolates recovered from symptomatic almond (cankers, shoot blight, and fruit rot) and Ficus trees (cankers) clustered into a single well-supported group (99 and 100\% ML and MP bootstrap values, respectively) that includes the ex-type $N$. dimidiatum CBS 145.78 and two isolates confirmed as Neoscytalidium novaehollandiae Pavlic, T. I. Burgess, M. J. Wingf. that cluster as a separate clade (94 and $98 \%$ ) to $N$. dimidiatum (Supplementary Fig. S1). Alignment of 64 BT2 sequences resulted in a 399-character dataset (228 characters were constant, 124 characters were parsimony informative, and 47 characters were parsimony uninformative). MP analysis produced two equally most-parsimonious trees of 287 steps and a CI and RI of 0.7551 and 0.8750 , respectively. ML and MP analyses revealed that $47 \mathrm{~N}$. dimidiatum strains clustered with strong support (99 and 99\%) with the ex-type sequence of $N$. dimidiatum CBS 145.78; unfortunately, no BT2 sequences were available for $N$. novaehollandiae for comparison (Supplementary Fig. S2). Alignment of 66 TEF-1 $\alpha$ sequences resulted in a 250-character dataset (64 characters were constant, 123 characters were parsimony informative, and 63 characters were parsimony uninformative). MP analyses produced eight mostparsimonious trees of 400 steps and a CI and RI of 0.7012 and 0.8055 , respectively. ML and MP analyses revealed that $47 N$. dimidiatum isolates clustered in a single strongly supported clade that includes the ex-type of $N$. dimidiatum and two isolates of $N$. novaehollandiae. The TEF-1 $\alpha$ analyses also revealed support for a subclade ( 84 and $97 \%$ ) that consisted of $43 \mathrm{~N}$. dimidiatum strains isolated from almond and fig and $N$. dimidiatum CBS 499.66 originally isolated from mango in Mali as a distinct lineage sister to a moderately supported group (79\% and no support) that includes strains of $N$. novaehollandiae and the ex-type of $N$. dimidiatum, thus suggesting a recent divergence between the two species and the large, strongly supported almond clade (Supplementary Fig. S3).

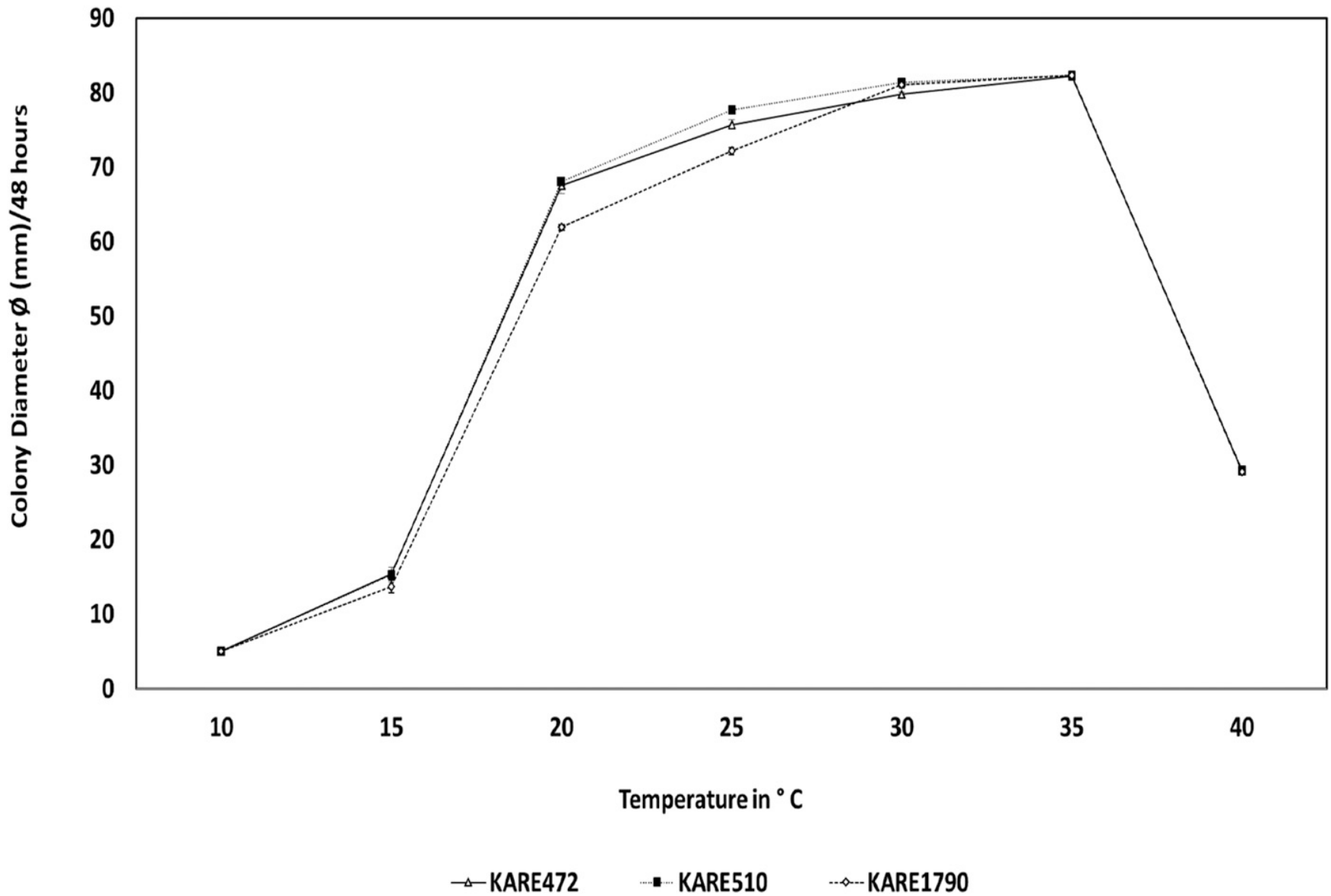

Fig. 4. Effect of the temperature on the mycelial growth of three isolates of Neoscytalidium dimidiatum (KARE472, KARE510, and KARE1790) on potato dextrose agar (48 $\mathrm{h}$ of incubation). 
The concatenated dataset consisted of 1,168 characters ( 618 characters were constant, 395 characters were parsimony informative, and 155 characters were parsimony uninformative). MP analysis produced seven equally most-parsimonious trees of 1,016 steps and a CI and RI of 0.7268 and 0.8446 , respectively. The topology of the concatenated dataset analysis was similar to the analyses of TEF- $1 \alpha$. All Neoscytalidium isolates clustered as a strongly supported monophyletic group (99 and 100\%) with moderate support for three lineages. Two isolates of $N$. novaehollandiae grouped with high support (99 and $99 \%$ ) on the backbone of the large Neoscytalidium clade, including four of our strains from fig and the ex-type of $N$. dimidiatum and another isolate of $N$. dimidiatum CBS 251.49. In all, 43 strains collected from almond and fig formed a sister clade with strong MP support $(96 \%)$ but low ML support $(<70 \%)$, suggesting that these strains may represent a cryptic species, whereby additional phylogenetically informative loci may provide more robust support (Fig. 2).

Morphological characterization. Morphological characteristics of the fungal isolates recovered from almond cankers, shoot blight, and fruit rot matched description of $N$. dimidiatum (Crous et al. 2006). All three strains examined produced rapidly growing colonies with an average growth rate of $4 \mathrm{~cm} /$ day and covering the surface of an $85-\mathrm{mm}$ PDA plate in $48 \mathrm{~h}$. On PDA medium, the mycelium began growth as a white or hyaline colony appearing powdery in the center, transitioned to an olive-green to greyish color, and finally turned dark-gray to black after 12 days (Fig. 3A). Colonies produced mycelia that disarticulated into 0- to 1-septate, cylindrical to round, hyaline to brown arthroconidia occurring singly or in arthric chains and averaged $9.4 \pm 1.2$ by $5.1 \pm 0.8 \mu \mathrm{m}$, with a length/width ratio of 1.85 (Fig. 3B and C). Pycnidia, produced after a 3- to 4-week incubation period, were black, irregularly shaped to ovoid, and occurred singly or in aggregates (Fig. 3D and E). Pycnidial conidia were hyaline, ellipsoidal to ovoid, and averaged $11.1 \pm 0.7$ by $5.5 \pm 0.5 \mu \mathrm{m}$, with a length/width ratio of 2.03 (Fig. 3F). The optimal growth temperature was 30 to $35^{\circ} \mathrm{C}$ for all three strains tested (Fig. 4).

Pathogenicity tests. Branch inoculations. In assay 1, gumming occurred near the infection sites as early as 2 weeks following inoculation; however, gumming was not observed in the mock-inoculated controls. After 1 month of incubation, the lesion lengths produced by $N$. dimidiatum averaged $15.83 \mathrm{~cm}$ for the cultivar Nonpareil and $20.44 \mathrm{~cm}$ for the cultivar Butte and were significantly longer $(P<$ 0.05 ) than the controls (average 0.31 and $2.67 \mathrm{~cm}$ for Nonpareil and Butte, respectively). The pathogen killed the underlying bark tissue and developed discolored longitudinal cankers around the inoculation site, with sap produced at the site of inoculation oozing on the shoot surface. Mock-inoculated controls showed no symptoms except faint discoloration around the wound site (Fig. 5). N. dimidiatum was reisolated from cankers produced in all the inoculated branches, thus completing Koch's postulates. $N$. dimidiatum was not isolated from mock-inoculated controls. Isolate identity was confirmed by the unique colony morphology of $N$. dimidiatum.

Inoculation of Carmel shoots with a spore suspension (assay 2) resulted in shoot cankers and amber sap production. On average, $90 \%$ of all branches inoculated with $N$. dimidiatum showed gumming that occurred near the inoculation site, while all control branches remained healthy and without any gumming or cankers. The pathogen was successfully $(100 \%)$ reisolated from all inoculated tissues (margins of cankers) and never isolated from mock-inoculated controls.

Fruit inoculations. Attached almond fruit inoculations using spore suspension of $N$. dimidiatum resulted in fruit rot (hull rot) and blighting of the leaves and spurs 10 days after inoculation. In all, $70 \%$ of the fruit inoculated developed fruit rot accompanied with leaf and spur blight; $20 \%$ of the inoculated fruit only expressed fruit rot, while the remaining $10 \%$ did not express symptoms on fruit but developed a few blighted leaves. The hulls, leaves, and spurs in all controls

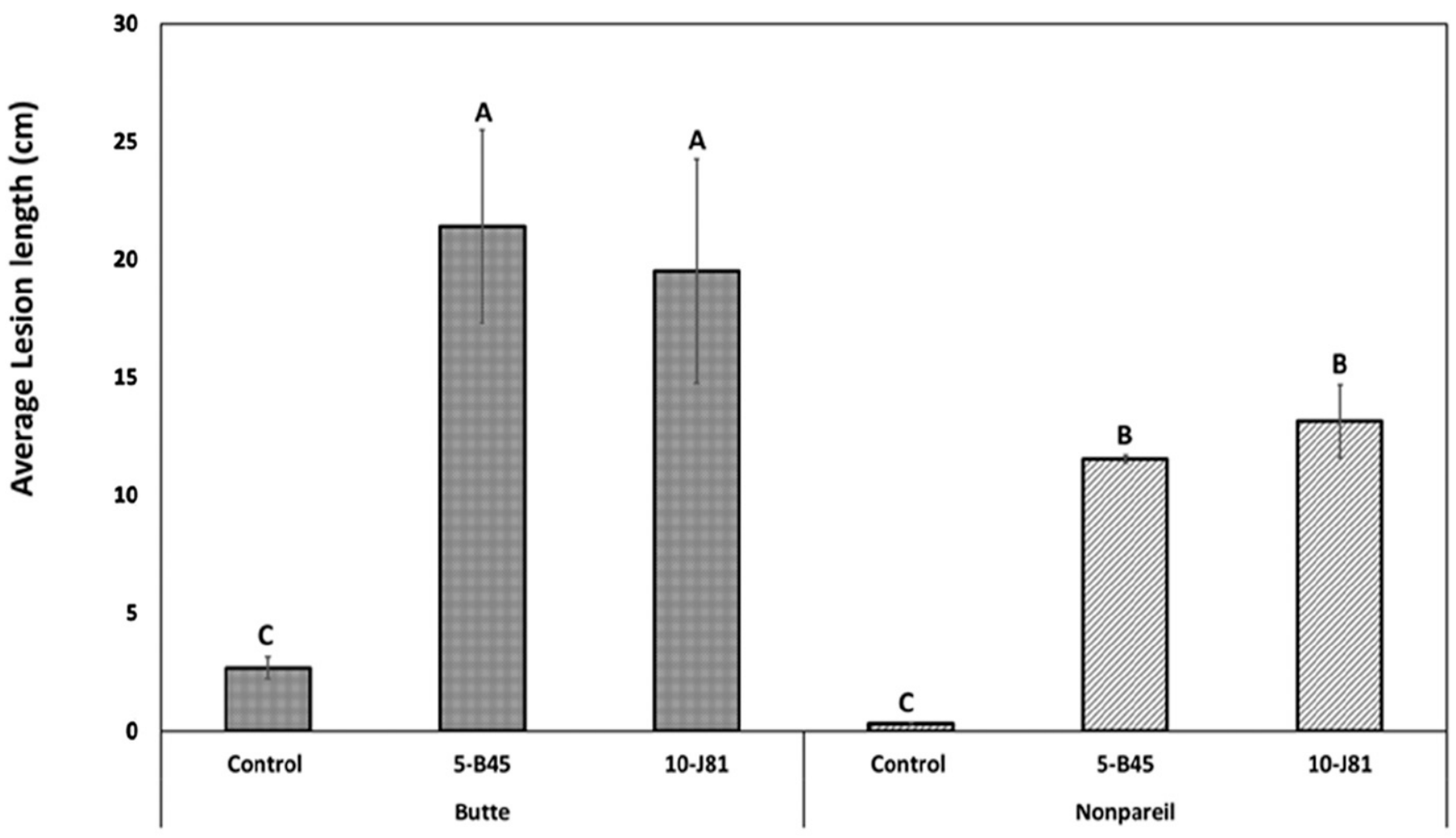

Treatments

Fig. 5. Average lesion length (in centimeters) resulting from inoculation with a mycelium plug of Neoscytalidium dimidiatum onto branches of two almond cultivars (Butte and Nonpareil). Vertical bars represent standard error of means. Letters above bars indicate treatments that were significantly different $(P<0.05)$. Note: control showed only faint discoloration and no gumming. 
remained healthy during the experiment. Reisolation of $N$. dimidiatum from the symptomatic fruit that developed sporulation on the inner surface of hulls was $100 \%$, whereas $N$. dimidiatum was not isolated from the controls.

\section{Discussion}

The present study recognizes $N$. dimidiatum causing canker, shoot blight, and fruit rot of almond in California. Symptoms include longitudinally expanding branch and trunk cankers, fruit (hull rot) rot, as well as the blight of fruit-bearing spurs and shoots. The identification of $N$. dimidiatum was supported by morphological examinations of the unique colony characteristics and other anamorphic morphologies typical of the species (Phillips et al. 2013). Identification was also confirmed using phylogenetic analyses of ITS, BT2, and TEF1- $\alpha$ sequence data. These analyses also revealed that isolates collected from different symptoms in almond (trunk and branch cankers, blighted shoots, and fruit rot) and various geographic locations represented a single species. Results of phylogenetic analyses also indicated that $N$. dimidiatum isolates from almond were genetically similar to other isolates from English walnut, mango, and human (Fig. 2).

$N$. dimidiatum has been reported from a wide range of woody plants around the world (Punithalingam and Waterston 1970; Sutton and Dyko 1989). It has been associated with mango branch dieback and canker symptoms, and produces rot lesions on mango fruit (Marques et al. 2013; Ray et al. 2010). N. dimidiatum was considered the most virulent species in pathogenicity studies among several other species of Botryosphaeriaceae (Marques et al. 2013). Symptoms of canker and fruit rot of almond caused by $N$. dimidiatum were, in many aspects, similar to those previously reported on mango (Ray et al. 2010). N. dimidiatum was isolated also from roots and stems of fig shrubs exhibiting symptoms of dieback (Ray et al. 2010). Mayorquin et al. (2016) reported $N$. hyalinum associated with citrus branch canker in the southern California desert; however, the correct name is $N$. dimidiatum because the name $N$. hyalinum was published invalidly by Phillips et al. (2013). In California, branch wilt of English walnut caused by $H$. toruloidea (syn. $N$. dimidiatum) has long been known to occur in the Central Valley (Paxton et al. 1964; Wilson 1947). Recently, $N$. dimidiatum has been considered an emerging pathogen of citrus and grapevine in California (Mayorquin et al. 2016; Rolshausen et al. 2013). These perennial crops are adjacent or in close proximity to almond orchards throughout the San Joaquin Valley, which suggests that cross infection may likely occurs among these crops.

In California almond, Botryosphaeria dothidea (Moug.) Ces. \& De Not. was originally reported as the main causal agent of band canker, a disease expressing patchy cankers with oozing sap at growth cracks produced on trunks (English et al. 1966). Later, the same authors also reported $H$. toruloidea (syn. $N$. dimidiatum) from cankers on trees affected with band canker. However, based on field observations and isolation results, these authors suggested that $H$. toruloidea was a secondary invader of cankered tissues because $B$. dothidea was much more frequently associated with cankers than $H$. toruloidea (English et al. 1975). Furthermore, B. dothidea was the only fungus isolated from the margin of apparently active cankers (English et al. 1975). More recently, Inderbitzin et al. (2010) reported seven species of Botryosphaeriaceae associated with band canker or cankers in the canopy but $N$. dimidiatum was not found. However, in our study, branch and trunk cankers of almond associated with $N$. dimidiatum appeared fairly widespread in California, which suggests a recent increase in the disease incidence. Sadowsky et al. (2007) showed that predisposition to disease induced by hot temperature $\left(34^{\circ} \mathrm{C}\right)$ is a prerequisite for infection of susceptible hosts by $N$. dimidiatum. Similarly, H. toruloidea causing branch wilt of walnut is known to grow best at high temperatures, and greater disease incidence occurs when temperatures are highest (Ogawa and English 1991). Our work confirmed that optimal growth of the fungus in vitro is near $35^{\circ} \mathrm{C}$, which is typical for a summer day in the Central Valley of California. English et al. (1975) showed that $H$. toruloidea was virulent only in summer and was unable to induce disease in January or March in
California. However, our pathogenicity studies conducted in February, June, and July 2015 showed that isolates of $N$. dimidiatum were pathogenic in almond independently of the time (month) of inoculation. In our study, the ability of $N$. dimidiatum to cause disease following February inoculation could be explained, in part, by climate change and increased winter temperatures in California as compared with 40 years ago. Indeed, the winter of 2015 was particularly dry and warm in California, with February temperatures averaging $13.9^{\circ} \mathrm{C}$ as compared with $9.4^{\circ} \mathrm{C}$ in 1975 . Almond cultivation also has increased considerably in the last decade in California and the use of intensive production practices such as clonal propagation of trees, mechanical harvest, and severe pruning, together with long periods of drought exposing trees to increased water stress, may have contributed to an exacerbation of this canker disease. In addition, it has been shown that trees subjected to stress become more susceptible to infection by Botryosphaeriaceae fungi (Ma et al. 2001).

The almond cultivar Butte was more susceptible than Nonpareil (Fig. 5), showing the longest lesion length of $21.4 \mathrm{~cm}$, on average, in inoculated branches, suggesting a potential spectrum of sensitivity among almond cultivars to canker. Additional experiments will be needed to test this hypothesis. Also, we report on the presence of abundant gumming following inoculations of shoots and branches in all almond cultivars tested. Symptoms of canker and abundant gumming caused by $N$. dimidiatum and boron toxicity can easily be confused. Symptoms of boron toxicity appear as excess gum exuding from stems, branches, shoots, and fruit. Identifying the cause of the gumming may help address crop losses due to $N$. dimidiatum infections. Our study revealed also that $N$. dimidiatum can cause fruit rot in almond with symptoms similar to those of hull rot disease of almond caused by Rhizopus stolonifer (Ehrenb.) Vuill. or Monilinia fructicola (G. Winter) Honey. Hull rot of almond appears as gray to brown lesions of the hull of maturing almond fruit, generally killing leaves near the infected fruit as well as the subtending spur or shoot (Teviotdale et al. 2001). N. dimidiatum also caused death of leaves, fruitful spurs, and shoots neighboring infected fruit. As with $R$. stolonifer and M. fructicola, N. dimidiatum also produces dense sporulation in the interior hull surface and pathogenesis mechanisms are presumed to be similar among all three fungi; infection of the inner hull occurs after the hull dehisces along the ventral suture (hull split) (Teviotdale et al. 2001). In this study, fruit rot caused by $N$. dimidiatum was found in only two orchards in Kern County; however, the disease frequency within these orchards was high. It is possible that $N$. dimidiatum fruit rot may have been overlooked in almond orchards in California due to its resemblance to hull rot. Further surveys will need to be conducted to investigate the actual distribution of almond fruit rot caused by $N$. dimidiatum in California as well as its relative importance with respect to hull rot caused by $R$. stolonifer and M. fructicola.

In conclusion, the present study identified $N$. dimidiatum as a new causal agent of canker, shoot blight, and fruit rot in almond, and this pathogen represents a new and emerging threat to the industry. This study represents the first detailed research concerning the phylogeny, morphology, distribution, and pathogenicity of $N$. dimidiatum on almond in California. Previous studies have shown that $N$. dimidiatum is important primarily as a wound pathogen infecting its host through freeze injury, sunburn, pruning wounds, or mechanical injury but that it does not infect uninjured bark tissue (Calavan and Wallace 1954). Field observation suggests that the pathogen infects almond branches and trunk through pruning wounds and cracks. Fruit most likely become infected when hulls split. Further research should aim at investigating the disease epidemiology as well as developing efficient control strategies to mitigate the impact of this new disease of almond in California.

\section{Acknowledgments}

We thank D. A. Doll, M. Culumber, and P. Gordon, University of California Cooperative Extension Farm Advisors, for sending the diseased samples; and M. Viveros, emeritus farm advisor, University of California Cooperative Extension Kern County, and C. Cucuk, Pest Control Adviser, for bringing the fruit hull rot phase of the disease to the attention of the authors and for providing orchards for sampling. 


\section{Literature Cited}

Adesemoye, A. O., Mayorquin, J. S., Wang, D. H., Twizeyimana, M., Lynch, S. C., and Eskalen, A. 2014. Identification of species of Botryosphaeriaceae causing Bot gummosis in citrus in California. Plant Dis. 98:55-61.

Almond Board of California. 2016. Global Usage. https://www.almonds.com/ consumers/about-almonds/global-almond-usage

Calavan, E. C., and Wallace, J. M. 1954. Hendersonula toruloidea Natrass on citrus in California. Phytopathology 44:635-639.

Carbone, I., and Kohn, L. M. 1999. A method for designing primer sets for speciation studies in filamentous ascomycetes. Mycologia 91:553-556.

Chen, S. F., Morgan, D. P., Hasey, J. K., Anderson, K., and Michailides, T. J. 2014a. Phylogeny, morphology, distribution, and pathogenicity of Botryosphaeriaceae and Diaporthaceae from English walnut in California. Plant Dis. 98: 636-652.

Chen, S. F., Morgan, D. P., and Michailides, T. J. 2014b. Botryosphaeriaceae and Diaporthaceae associated with panicle and shoot blight pistachio in California, USA. Fungal Divers. 67:157-179.

Crous, P. W., Slippers, B., Wingfield, M. J., Rheeder, J., Marasas, W. F. O., Philips, A. J. L., Alves, A., Burgess, T., Barber, P., and Groenewald, J. Z. 2006. Phylogenetic lineages in the Botryosphaeriaceae. Stud. Mycol. 55:235-253.

Doll, D. A., Rolshausen, P. E., Pouzoulet, J., and Michailides, T. J. 2015. First report of Dothiorella iberica causing trunk and scaffold cankers of almond in California. Plant Dis. 99:1185.

English, H., Davis, J. R., and De Vay, J. E. 1966. Dothiorella canker, a new disease of almond trees in California. Phytopathology 56:146.

English, H., Davis, J. R., and De Vay, J. E. 1975. Relationship of Botryosphaeria dothidea and Hendersonula toruloidea to a canker disease of almond. Phytopathology 65:114-122.

Farr, D. F., Elliott, M., Rossman, A. Y., and Edmonds, R. L. 2005. Fusicoccum arbuti sp. nov, causing cankers on Pacific madrone in western North America with notes on Fusicoccum dimidiatum, the correct name for Scytalidium dimidiatum and Nattrassia mangiferae. Mycologia 97:730-741.

Glass, N. L., and Donaldson, G. C. 1995. Development of primer sets designed for use with the PCR to amplify conserved genes from filamentous Ascomycetes. Appl. Environ. Microbiol. 61:1323-1330.

Gramaje, D., Agustí-Brisach, C., Pérez-Sierra, A., Moralejo, E., Olmo, D., Mostert, L., Damm, U., and Armengol, J. 2012. Fungal trunk pathogens associated with wood decay of almond trees on Mallorca (Spain). Persoonia 28:1-13.

Inderbitzin, P., Bostock, R. M., Trouillas, F. P., and Michailides, T. J. 2010. A six locus phylogeny reveals high species diversity in Botryosphaeriaceae from California almond. Mycologia 102:1350-1368.

Lawrence, D. P., Peduto Hand, F. P., Gubler, W. D., and Trouillas, F. P. 2017a. Botryosphaeriaceae species associated with dieback and canker disease of bay laurel in northern California with the description of Dothiorella californica sp. nov. Fungal Biol. 121:347-360.

Lawrence, D. P., Travadon, R., Nita, M., and Baumgartner, K. 2017b. TrunkDiseaseID.org: A molecular database for fast and accurate identification of fungi commonly isolated from grapevine wood. Crop Prot. 102:110-117.

Lynch, S. C., Eskalen, A., Zambino, P. J., Mayorquin, J. S., and Wang, D. H. 2013. Identification and pathogenicity of Botryosphaeriaceae species associated with coast live oak (Quercus agrifolia) decline in southern California. Mycologia 105:125-140.

Ma, Z., Morgan, D. P., and Michailides, T. J. 2001. Effects of water stress on Botryosphaeria blight of pistachio caused by Botryosphaeria dothidea. Plant Dis. 85:745-749.

Maddison, W. P., and Maddison, D. R. 2016. Mesquite: A modular system for evolutionary analysis, version 3.10 Online publication. http://mesquiteproject.org

Marques, M. W., Lima, N. B, de Morais, M. A., Jr., Michereff, S. J., Phillips, A. J. L., and Câmara, M. P. S. 2013. Botryosphaeria, Neofusicoccum, Neoscytalidium and Pseudofusicoccum species associated with mango in Brazil. Fungal Divers. 61: 195-208.

Mayorquin, J. S., Wang, D. H., Twizeyimana, M., and Eskalen, A. 2016. Identification, distribution, and pathogenicity of Diatrypaceae and Botryosphaeriaceae associated with citrus branch canker in the Southern California desert. Plant Dis. 100: 2402-2413.

McDonald, V., and Eskalen, A. 2011. Botryosphaeriaceae species associated with avocado branch cankers in California. Plant Dis. 95:1465-1473.

Moral, J., Muñoz-Díez, C., González, N., Trapero, A., and Michailides, T. J. 2010. Characterization and pathogenicity of Botryosphaeriaceae species collected from olive and other hosts in Spain and California. Phytopathology 100: 1340-1351.

Nattrass, R. M. 1933. A new species of Hendersonula (H. toruloidea) on deciduous trees in Egypt. Br. Mycol. Soc. Trans. 18:189-IN2.
Ogawa, J. M., and English, H. 1991. Diseases of Temperate Zone Tree Fruit and Nut Crops. ANR 3345. University of California, Oakland.

Olmo, D., Armengol, J., León, M., and Gramaje, D. 2016. Characterization and pathogenicity of Botryosphaeriaceae species isolated from almond trees on the Island of Mallorca (Spain). Plant Dis. 100:2483-2491.

Pavlic, D., Slippers, B., Coutinho, T. A., and Wingfield, M. J. 2009. Multiple gene genealogies and phenotypic data reveal cryptic species of the Botryosphaeriaceae: A case study on the Neofusicoccum parvum/N. ribis complex. Mol. Phylogenet. Evol. 51:259-268.

Pavlic, D., Wingfield, M. J., Barber, P., Slippers, B., Harder, G. E. S., and Burgess, T. I. 2008. Seven new species of the Botryosphaeriaceae from baobab and other native trees in Western Australia. Mycologia 100:851-866.

Paxton, J. D., Wilson, E. E., and Davis, J. R. 1964. Branch wilt disease of fig caused by Hendersonula toruloidea. Plant Dis. Rep. 48:142.

Phillips, A. J. L., Alves, A., Abdollahzadeh, J., Slippers, B., Wingfield, M. J., Groenewald, J. Z., and Crous, P. W. 2013. The Botryosphaeriaceae: Genera and species known from culture. Stud. Mycol. 76:51-167.

Phillips, A. J. L., Alves, A., Correia, A., and Luque, J. 2005. Two new species of Botryosphaeria with brown, 1-septate ascospores and Dothiorella anamorphs. Mycologia 97:513-529.

Punithalingam, E., and Waterston, J. M. 1970. Hendersonula toruloidea. CMI Descriptions of Pathogenic Fungi and Bacteria. No. 274. Commonwealth Mycological Institute, Kew, Surrey, UK

Ray, J. D., Burgess, T. I., and Lanoiselet, V. M. 2010. First record of Neoscytalidium dimidiatum and $N$. novaehollandiae on Mangifera indica and N. dimidiatum on Ficus carica in Australia. Australas. Plant Dis. Notes 5:48-50.

Rolshausen, P. E., Akgül, D. S., Perez, R., Eskalen, A., and Gispert, C. 2013. First report of wood canker caused by Neoscytalidium dimidiatum on grapevine in California. Plant Dis. 97:1511.

Sadowsky, A., Solel, Z., and Sztejnberg, A. 2007. Effect of heat-stress predisposition on the development of Scytalidium wilt of 'Star Ruby' grapefruit, caused by Scytalidium lignicola. Eur. J. Plant Pathol. 117:123-127.

Slippers, B., Boissin, E., Phillips, A. J. L., Groenewald, J. Z., Lombard, L., Wingfield, M. J., Postma, A., Burgess, T., and Crous, P. W. 2013. Phylogenetic lineages in the Botryosphaeriales: A systematic and evolutionary framework. Stud. Mycol. 76:31-49.

Slippers, B., Crous, P. W., Denman, S., Coutinho, T. A., Wingfield, B. D., and Wingfield, M. J. 2004. Combined multiple gene genealogies and phenotypic characters differentiate several species previously identified as Botryosphaeria dothidea. Mycologia 96:83-101.

Slippers, B., Smit, W. A., Crous, P. W., Coutinho, T. A., Wingfield, B. D., and Wingfield, M. J. 2007. Taxonomy, phylogeny and identification of Botryosphaeriaceae associated with pome and stone fruit trees in South Africa and other regions of the world. Plant Pathol. 56:128-139.

Slippers, B., and Wingfield, M. J. 2007. Botryosphaeriaceae as endophytes and latent pathogens of woody plants: Diversity, ecology and impact. Fungal Biol. Rev. 21:90-106.

Sutton, B. C., and Dyko, B. J. 1989. Revision of Hendersonula. Mycol. Res. 93: 466-488.

Tamura, K., Stecher, G., Peterson, D., Filipski, A., and Kumar, S. 2013. MEGA6: Molecular evolutionary genetics analysis version 6.0. Mol. Biol. Evol. 30: 2725-2729.

Teviotdale, B. L., Goldhamer, D. A., and Viveros, M. 2001. Effects of deficit irrigation on hull rot disease of almond trees caused by Monilinia fructicola and Rhizopus stolonifer. Plant Dis. 85:399-403.

Úrbez-Torres, J. R., and Gubler, W. D. 2009. Pathogenicity of Botryosphaeriaceae species isolated from grapevine cankers in California. Plant Dis. 93:584-592.

Úrbez-Torres, J. R., Leavitt, G. M., Voegel, T., and Gubler, W. D. 2006. Identification and distribution of Botryosphaeria species associated with grapevines cankers in California. Plant Dis. 90:1490-1503.

Úrbez-Torres, J. R., Peduto, F., Vossen, P. M., Krueger, W. H., and Gubler, W. D. 2013. Olive twig and branch dieback: Etiology, incidence, and distribution in California. Plant Dis. 97:231-244.

White, C. L., Halleen, F., Fischer, M., and Mostert, L. 2011. Characterisation of the fungi associated with esca diseased grapevines in South Africa. Phytopathol. Mediterr. 50:S204-S223.

White, T. J., Bruns, T., Lee, S., and Taylor, J. 1990. Amplification and direct sequencing of fungal ribosomal RNA genes for phylogenetics. Pages 315-322 in: PCR Protocols: A Guide to Methods and Applications. M. A. Innis, D. H. Gelfand, J. J. Snisky, and T. J. White, eds. Academic Press, San Diego, CA.

Wilson, E. E. 1947. The branch wilt of Persian walnut trees and its cause. Hilgardia 17:413-436. 